\title{
С.В. КРАСНИКОВ
}

\section{МОДЕЛИРОВАНИЕ И АНАЛИЗ ВИБРАЦИОННЫХ ХАРАКТЕРИСТИК КОРПУСА ПАРОВОЙ ТУРБИНЫ БОЛЬШОЙ МОЩНОСТИ}

Проведено аналіз динамічної пружності опорних елементів корпусу парової турбіни великої потужності. Об'єктом дослідження є гнучка частина парової турбіни - циліндр низького тиску. Для дослідження використана парова турбіна великої потужності, що містить кілька типових корпусів. Для моделювання та проведення чисельних розрахункових досліджень використаний метод кінцевих елементів. Побудовано геометричні й кінцево-елементні моделі корпуса парової турбіни 3 урахуванням міцності опорної конструкції. Проведено розрахунки змушених коливань на декількох моделях. Отримано залежності амплітуд коливань від розподілу по опорних поверхнях з урахуванням двох варіантів міцності опорної системи. Отримані результати дають якісну оцінку динамічної міцності опорних поверхонь корпуса парової турбіни при двох розглянутих моделях пружності опори турбоагрегату.

Ключові слова: вібрація, парова турбіна, циліндр низького тиску, метод скінчених елементів, амплітуди вимушених коливань, фундамент.

Проведен анализ динамической жесткости опорных элементов корпуса паровой турбины большой мощности. Объектом исследования является гибкая часть паровой турбины - цилиндр низкого давления. Для исследования использована паровая турбина, которая содержит несколько типовых корпусов. Для моделирования и проведения численных расчетных исследований использован метод конечных элементов. Построены геометрические и конечно-элементные модели корпуса паровой турбины с учетом жесткости опорной конструкции. Проведены расчеты вынужденных колебаний на нескольких моделях. Получены зависимости амплитуд колебаний от распределения по опорным поверхностям с учетом двух вариантов жесткости опорной системы. Полученные результаты дают качественную оценку динамической жесткости опорных поверхностей корпуса паровой турбины при двух рассмотренных моделях упругости опоры турбоагрегата.

Ключевые слова: вибрация, паровая турбина, цилиндр низкого давления, метод конечных элементов, амплитуды вынужденных колебаний, фундамент.

The analysis of the dynamic elasticity of the supporting elements of the body of a high power steam turbine is carried out. The object of the study is a flexible part of the steam turbine - a low pressure cylinder. For research, a steam turbine of high power, containing several typical buildings, was investigated. For modeling and conducting numerical calculations, the method of finite elements was used. The geometric and finite element models of the steam turbine body are constructed taking into account the strength of the supporting structure. Calculated forced oscillations on several models. The dependences of oscillation amplitudes on distribution on supporting surfaces were obtained taking into account two variants of the strength of the reference system. The obtained results give a qualitative estimate of the dynamic strength of the supporting surfaces of the body of the steam turbine under the two models of the elasticity of the turbine support.

Keywords: vibration, steam turbine, low pressure case, finite element method, amplitude of forced oscillations, foundation.

Введение. Страны с растущей экономикой характеризуются высоким промышленным уровнем, который требует развитой энергетической системы. Рост энергопотребления привел в развитых стран к необходимости импорта электроэнергии из бывших высокоразвитыми промышленных районов или стран с более высоким уровнем развития энергетики, одной из которых является Украина. В большинстве развитых стран энергетика базируется в первую очередь на тепловых и атомных электростанциях, которые состоят из энергоблоков и другого оборудования. Как правило, страны с высокоразвитой энергетикой массово используют энергоблоки средней и большой мощности. Бурный рост промышленности в конце прошлого века привел к созданию на нашей родине и за границей паровых турбин мощностью 1000 МВт и выше. Этот, достигнутый в нашем отечестве, результат в создании энергетического оборудования большой мощности до сих пор остается непревзойденным, несмотря на опережающие темпы развития промышленности в Китае и других странах. Уровень передовой техники ПАО «Турбоатом» и концерна ПАО «Силовые машины» остается востребованным в странах, которые выбирают качество и надежность вместо поли- тических амбиций. Эти два фактора являются определяющими для грамотного заказчика. Надежность работы энергоблоков в значительной степени зависит от уровня вибраций оборудования $[1,2]$. Основным источником вибраций является небаланс ротора, который является неустранимым фактором. Вибрация от ротора передается на все остальные части системы турбоагрегатфундамент-основание. При этом наибольшую чувствительность имеют части указанной системы с наименьшей жесткостью - корпуса цилиндров низкого давления. В турбинах мощностью 1000 МВт и выше этих корпусов несколько. Это приводит к необходимости детального анализа вибрационных характеристик корпусов цилиндров низкого давления [3].

Цель работы. Необходимо исследовать амплитудно-частотную зависимость вибрационных характеристик корпуса паровой турбины для анализа его взаимосвязи с фундаментом турбоагрегата. Объектом проведенных исследований является корпус цилиндра низкого давления паровой турбины мощностью 1100 МВт. Предметом исследования является динамическая жесткость опорных элементов корпуса паровой турбины большой мощности. 
Математическая модель. Для моделирования и анализа вибрационных характеристик используется метод конечных элементов. Основной функционал в общем виде:

$$
L(t, O, q)=R(t)
$$

где $O$ - различные состояния связи корпуса турбины с фундаментом; $L$-уравнение Лагранжа 2-го рода; $q-$ обобщенные перемещения; $R$ - внешние силы.

В методе конечных элементов [4] выражение (1) обычно записывается в следующем матричном виде:

$$
[M]\{\ddot{q}(t)\}+[C]\{\dot{q}(t)\}+[K]\{q(t)\}=0,
$$

где $M$ - матрица масс, $C$ - матрица демпфирования, $K$ - матрица жесткости.

Амплитуды вынужденных колебаний из уравнения (2) находятся на основе следующего выражения:

$$
\begin{gathered}
\{A\}=V\left[\operatorname{diag} \frac{e^{i \varphi_{j}}}{\sqrt{\left(p_{j}^{2}-\omega^{2}\right)^{2}+4 \omega^{2} p_{j}^{2} n_{j}^{2}}}\right] V^{T}\left\{R_{0}\right\} ; \\
\operatorname{tg} \varphi_{j}=\frac{2 \omega p_{j} n_{j}}{p_{j}^{2}-\omega^{2}},
\end{gathered}
$$

де $\{A\}$ - вектор амплитуд вынужденных колебаний; $V$ матрица собственных форм системы; $p_{j}-j$-я собственная частота системы; $n_{j}-$ коэффициент затухания $j$-й собственной формы системы; $\omega$ - частота внешних сил.

Собственная частота системы $p_{j}$ определяется из формулы (4):

$$
\operatorname{det}\left[K-p_{j}^{2} M\right]=0 \text {. }
$$

Описание расчетной модели. На основе ранее созданных геометрических моделей корпуса цилиндра низкого давления построен ряд конечно-элементных моделей. Для анализа вибрационных характеристик, который проведен в данной работе, использованы две модели. Внешний вид моделей показан на рис. 1. Вертикальная жесткость связи корпуса с фундаментом моделировалась в обеих моделях системой жесткостей. Отличие между расчетными моделями заключается в различной связи с корпуса турбины с фундаментом. У модели Т1 горизонтальные перемещения в опорах корпуса турбины на фундамент отсутствуют, а

\begin{tabular}{|c|c|c|c|c|c|}
\hline \multirow{2}{*}{$\begin{array}{l}\text { Назва } \\
\text { ние } \\
\text { мо- } \\
\text { дели }\end{array}$} & \multirow{2}{*}{$\begin{array}{c}\text { Верти- } \\
\text { кальная } \\
\text { жесткость, } \\
\text { Н/м }\end{array}$} & \multicolumn{4}{|c|}{ Количество } \\
\hline & & Узлов & $\begin{array}{c}\text { Элемен- } \\
\text { тов }\end{array}$ & $\begin{array}{c}\text { Степе- } \\
\text { ней } \\
\text { свободы }\end{array}$ & $\begin{array}{c}\text { Резо- } \\
\text { нансов } \\
0-55 \text { ГЦ }\end{array}$ \\
\hline T1 & $10^{12}$ & 13183 & 15135 & 78873 & 325 \\
\hline $\mathrm{T} 2$ & $10^{8}$ & 13270 & 15222 & 78876 & 334 \\
\hline
\end{tabular}
в модели Т2 эти перемещения моделируются с помощью системы жесткостей [5 - 9]. Характеристики расчетных моделей приведены в табл. 1.

Таблица 1 - Параметры конечно-элементных моделей

Для модели Т1 были проведены статический расчет при гравитационной нагрузке и расчет амплитуд вынужденных колебаний при нагружении единичной силой вблизи центра масс. Результаты динамического расчета были пересчитаны к эквиваленту статической гравитационной нагрузки, а результаты статического наоборот. Полученные данные этих вычислений приведены в табл. 2 и на рис. 2.

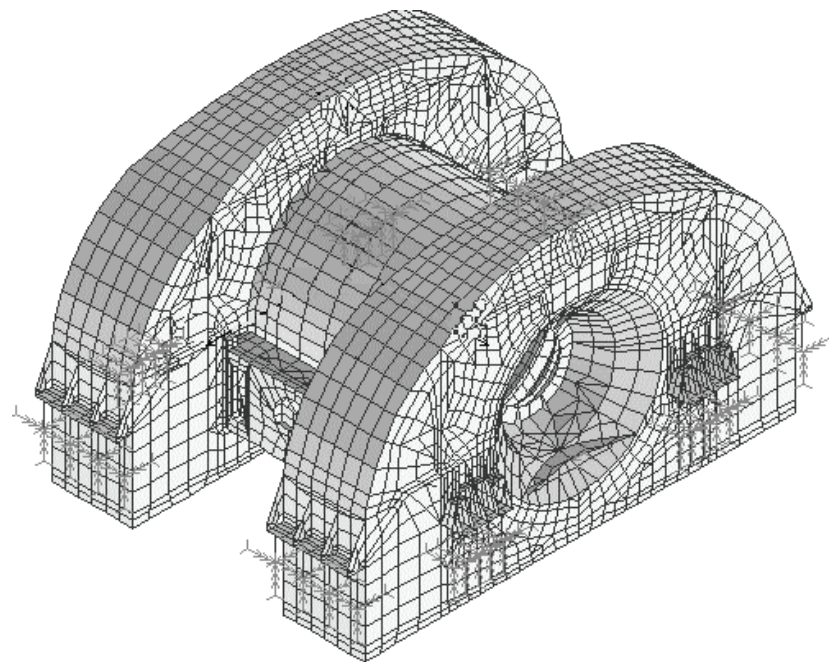

Рисунок 1 - Расчетная модель

Таблица 2 - Анализ перемещений для модели Т1 при жесткости $10^{12} \mathrm{H} / \mathrm{M}$

\begin{tabular}{|c|c|c|c|c|}
\hline $\begin{array}{c}\text { Тип рас- } \\
\text { чета }\end{array}$ & $\begin{array}{c}\text { Перемеще- } \\
\text { ния и ампли- } \\
\text { туда при 0 } \\
\text { Гц, м }\end{array}$ & $\begin{array}{c}\text { По- } \\
\text { греш- } \\
\text { ность, } \\
\%\end{array}$ & $\begin{array}{c}\text { Пересчет с } \\
\text { весом, м }\end{array}$ & Отличие, м \\
\hline Статика & $4,202 \mathrm{e}-004$ & 0,9 & $1,0987 \mathrm{e}-10$ & $5,4235 \mathrm{e}-11$ \\
\hline $\begin{array}{c}\text { Динами- } \\
\text { ка }\end{array}$ & $1,6418 \mathrm{e}-010$ & 2,4 & $6,131 \mathrm{e}-4$ & $1,929 \mathrm{e}-4$ \\
\hline
\end{tabular}

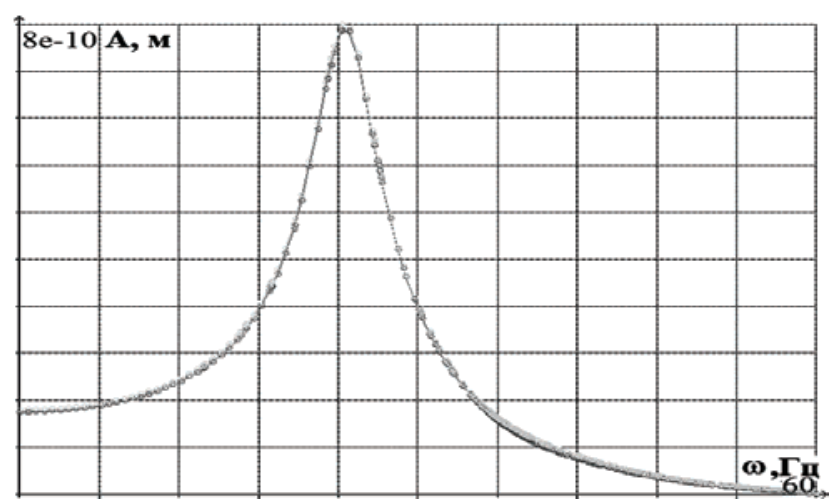

Рисунок 2 - Амплитуды вынужденных колебаний при нагружении единичной силой вблизи центра масс

Из табл. 2 видно, что различие между результатами вычислений не более 2,4 \%. Это доказывает сходимость и точность вычислений вибрационных характеристик. Кроме этого, точность определения амплитуд колебаний подтверждается проведенными ранее исследованиями, а также выбранной на основе них степени дискретизации расчетных моделей $[10,11]$.

Из табл. 2 видим, что для амплитуд вынужденных колебаний диапазон амплитуд имеет разброс около $5,4235 \cdot 10^{11}$ м, что на порядок отличается от максимальной амплитуды вынужденных колебаний в рассматриваемом диапазоне.

Результаты численных исследований. Для моделей Т1, Т2 проведены расчеты амплитуд вынужденных колебаний в контрольных точках при различном нагружении. На рис. 3 показано расположение контрольных точек корпуса ЦНД. Две из них располагаются в так называемых «фикспунктах» и обозначены буквой «ф». 
Остальные располагаются в нижней части опор на ребpax жесткости. Нагружение проводилось отдельно по каждой опоре в каждом из трех направлений $X, Y, Z$. Нагрузка была распределена по контрольным точкам опоры и в сумме равна 1 Н. При одном варианте нагружения (например в точках опоры 1 по оси Y) амплитуды вынужденных колебаний вычислялись во всех контрольных точках во всех трех направлениях. Поскольку конструкция имеет плоскость симметрии, то нагружение проводилось только по опорам 1-4. Трение рассматривалось конструкционное и учитывалось с помощью модального коэффициента демпфирования величиной 0,1 .

В результате расчетов были получены зависимости амплитуд вынужденных колебаний контрольных точек от нагружения в одном направлении в каждой из опор.

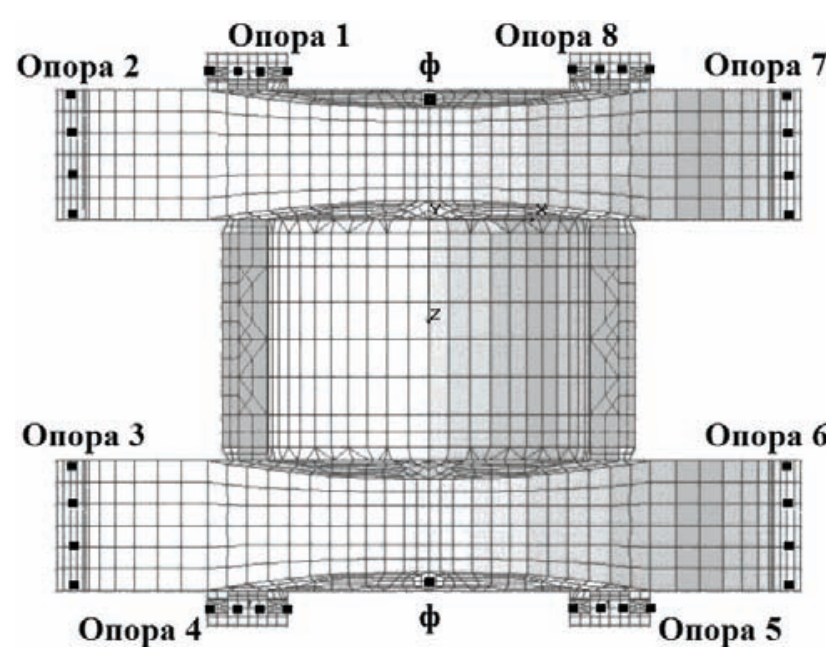

Рисунок 3 - Расположение опор и контрольных точек корпуса ЦНД

Типичные зависимости амплитуд колебаний в контрольных точках от частоты показаны на рис. 4-7. На этих рисунках вертикальная координата является амплитудой колебаний (м), а горизонтальная - частота вынуждающей нагрузки (0 - 60 Гц). Модель корпуса ЦНД - Т2.

Общий анализ полученных зависимостей показал, что они качественно близки для двух групп опор: 1, 4, 5 , 8 (первая) и 2, 3, 6, 7 (вторая). На рис. 4 и 5 показаны графики амплитуд колебаний точек опоры 2 второй группы в направлении Y и X при нагружении в этих же точках и направлениях. Соответствующие зависимости для точек опор первой группы имеют следующие отличия от графиков приведенных на рис. 4 и 5:

- меньший разброс амплитуд колебаний точек одной опоры;

- качественное совпадение в диапазоне 0 - 25 Гц;

- меньшее количество выраженных резонансов в диапазоне $25-50$ Гц.

На рис. 6 и 7 показаны графики амплитуд колебаний точек опор 1 и 2 в направлении $Z$. Из этих рисунков видно, что в диапазоне $0-25$ Гц они существенно отличаются по количеству выраженных резонансов и величинам амплитуд колебаний. В диапазоне 25 - 50 Гц графики имеют схожий качественный вид с отсутствием ярко выраженных резонансов.

Таким образом опоры 2 являются более гибкими, чем опоры 1.

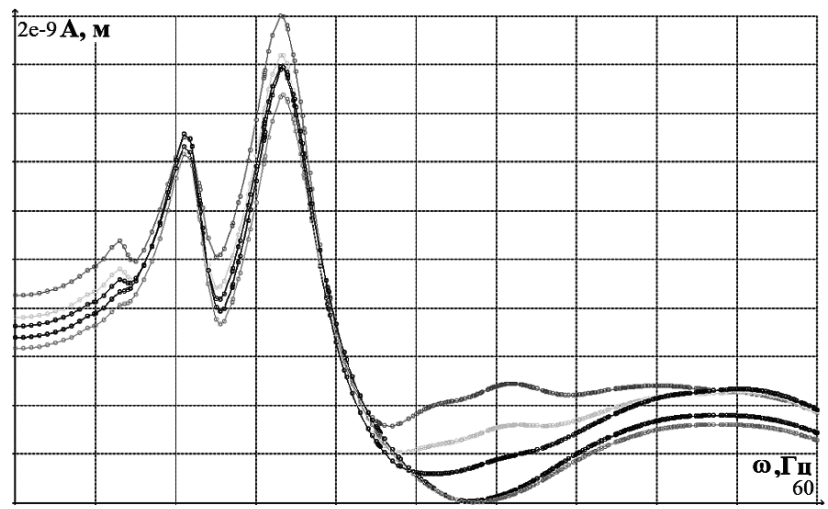

Рисунок 4 - Амплитуды колебаний точек опоры 2 в направлении $Y$

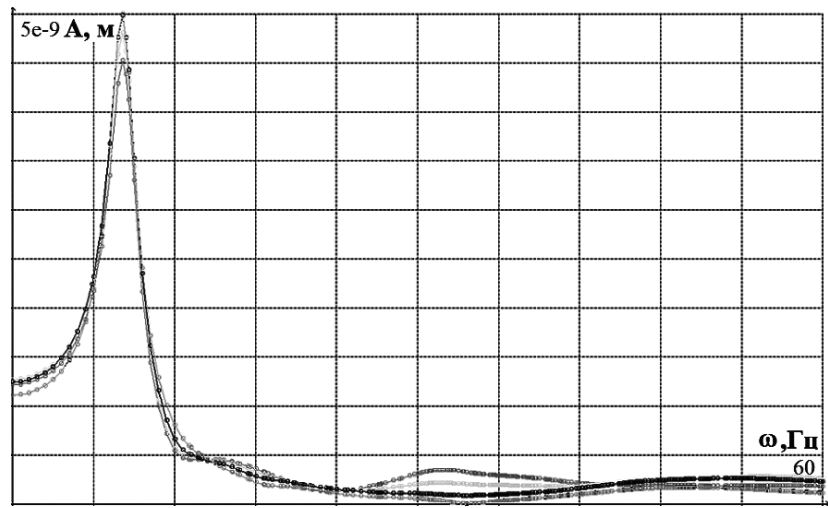

Рисунок 5 - Амплитуды колебаний точек опоры 2 в направлении $X$

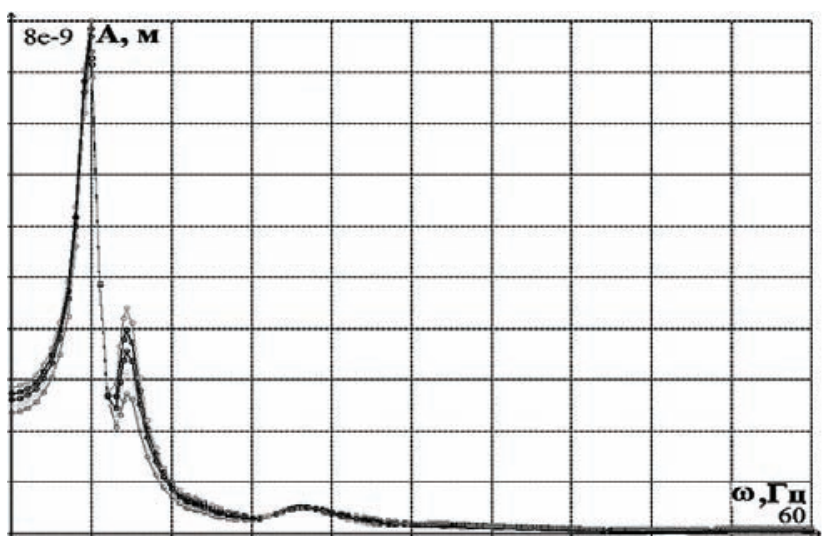

Рисунок 6 - Амплитуды колебаний точек опоры 1 в направлении $Z$

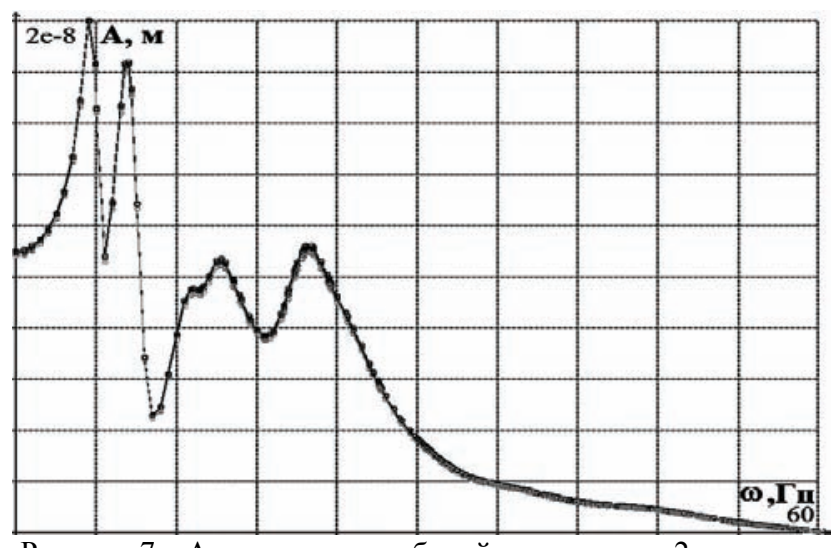

Рисунок 7 - Амплитуды колебаний точек опоры 2 в направлении $Z$ 
Выводы. На основе построенных геометрических моделей созданы расчетные модели корпуса ЦНД паровой турбины большой мощности. Проведены расчеты вынужденных колебаний на двух моделях. Получены зависимости амплитуд вынужденных колебаний контрольных точек при разных вариантах нагружения корпуса ЦНД. Получены распределения амплитуд колебаний на каждой опорной поверхности корпуса ЦНД. В результате анализа выделено две группы опор, с качественно сходными зависимостями колебаний внутри каждой группы.

\section{Список литературы:}

1. Рунов Б.Т. Исследование и устранение вибрации паровых турбоагрегатов / Б.Т. Рунов. - М.: Энергоиздат, 1982. $-352 \mathrm{c}$.

2. Шульженко Н.Г. Численный анализ колебаний систем турбоагрегат-фундамент / Н.Г. Шульженко, Ю.С. Воробъев. - К.: Наук. думка, 1991. - 232 с.

3. HITACHI. Turbine and Generator Foundation Design and construction \& recommendation. - Tokyo: Japan, 2009. - 104 p.

4. Еременко С.Ю. Методы конечных элементов в механике деформируемых тел / С.Ю. Еременко. - Х.: Основа, 1991. - $271 \mathrm{c}$

5. Zhiqiang $H u$, A Seismic Analysis on Steam Turbine Considering Turbine and Foundation Interaction / Zhiqiang $\mathrm{Hu}$, Wei Wang, Puning Jiang, Qinghua Huang, Jianhua Wang, Sihua Xu, Jin He, Lei Xiao // ASME Turbo Expo 2014: Turbine Technical Conference and Exposition. - Vol. 1B. - Düsseldorf: International Gas Turbine Institute, 2014. - PP. V01BT27A041. - 8 p.

6. Alan Turnbull Corrosion pitting and environmentally assisted small crack growth / Alan Turnbull // Proceedings. Mathematical, Physical, and Engineering Sciences. - London: The Royal Society, 2014. - PP. 20140254, 19 p.

7. Adhhikari Sukanta Turbo-Generator Foundation / Adhhikari Sukanta // Structural Engineering Forum of India. New Delhi: SEFI, 2010. - P.1-19.

8. Chowdhury Indrajit Dynamics of Structure and foundation a unified approach / Chowdhury Indrajit, Dasguptu P. Shambhu. - Leiden: CRC Press, 2009. - 616 p.

9. Gu Ping New dynamic participation factor for turbine generator foundation / Gu Ping // Practice Periodical on Structural Design and Construction. - VA.:American Society of Civil Engineers, 2009. - № 15(1). - P. 54-62.

10. Жовдак В.О. Решение задачи статистической динамики машиностроительных конструкций с учетом случайно- го изменения параметров / В.О. Жовдак, С.В. Красников, O.С. Степченко // Проблемы машиностроения. - Х.: Контраст, 2004. - Т. 7, № 3. - С. 39-47.

11. Красніков С.В. Комп'ютерне моделювання багатокорпусного турбоагрегату та аналіз його вібраційних характеристик / С.В. Красніков, О.С. Степченко, А.В. Торянік // Машинознавство. - Львів: Кінпатрі, 2009. - № 2. - С. 27-33.

\section{Bibliography (transliterated):}

1. Runov B.T. Issledovanie i ustranenie vibracii parovyh turboagregatov. Moscow: Energoizdat, 1982. 352 p.

2. Shul'zhenko N.G., Vorob'ev Yu.S. Chislennyj analiz kolebanij sistem turboagregat-fundament. Kyyiv: Naukova dumka, 1991. $232 \mathrm{p}$.

3. HITACHI. Turbine and Generator Foundation Design and construction \& recommendation. Tokyo: Japan, 2009. 104 p.

4. Eremenko S.Yu. Metody konechnyh elementov v mehanike deformiruemyh tel. Kharkiv: Osnova, 1991. $271 \mathrm{p}$.

5. Zhiqiang $\mathrm{Hu}$, Wei Wang, Puning Jiang, Qinghua Huang, Jianhua Wang, Sihua Xu, Jin He and Lei Xiao. A Seismic Analysis on Steam Turbine Considering Turbine and Foundation Interaction. ASME Turbo Expo 2014: Turbine Technical Conference and Exposition. Vol. 1B. Düsseldorf: International Gas Turbine Institute, 2014. PP. V01BT27A041, 8 p.

6. Alan Turnbull. Corrosion pitting and environmentally assisted small crack growth. Proceedings. Mathematical, Physical, and Engineering Sciences. London: The Royal Society, 2014. PP. 20140254, 19 p.

7. Adhhikari Sukanta. Turbo-Generator Foundation. Structural Engineering Forum of India. New Delhi: SEFI, 2010. P. 1-19.

8. Chowdhury Indrajit, Dasguptu P. Shambhu Dynamics of Structure and foundation a unified approach. Leiden: CRC Press, 2009. $616 \mathrm{p}$.

9. Gu Ping New dynamic participation factor for turbine generator foundation Practice Periodical on Structural Design and Construction. VA.: American Society of Civil Engineers, 2009. No 15(1). P. 54-62.

10. Zhovdak V.O., Krasnikov S.V., Stepchenko O.S. Reshenie zadachi statisticheskoj dinamiki mashinostroitel'nyh konstrukcij s uchetom sluchajnogo izmeneniya parametrov. Problemy mashinostroeniya. Kharkiv: Kontrast, 2004. Vol. 7, No 3. P. 39-47.

11. Krasnikov S.V., Stepchenko O.S., Toryanik A.V. Komp'yuterne modelyuvannya bahatokorpusnoho turboahrehatu ta analiz joho vibracijnykh kharakterystyk./ Mashynoznavstvo. L'viv: Kinpatri, 2009. No 2. P. 27-33.

Поступила (received) 20.09.2017

\section{Бібліографічні описи / Библиографические описания / Bibliographic descriptions}

Моделювання та аналіз вібраційних характеристик корпуса парової турбіни великої потужності / С.В. Красніков // Вісник НТУ «ХПІ». Серія: Динаміка і міцність машин. - Х.: НТУ «ХПІ», 2017. - № 39 (1261). - С. 23-26. - Бібліогр.: 11 назв. - ISSN 2078-9130.

Моделирование и анализ вибрационных характеристик корпуса паровой турбины большой мощности / С.В. Красников // Вісник НТУ «ХПІ». Серія: Динаміка і міцність машин. - Х.: НТУ «ХПІ», 2017. - № 39 (1261). - С. 23-26. - Бібліогр.: 11 назв. - ISSN 2078-9130.

Modeling and analysis of vibration characteristics of high power steam turbine case / S.V. Krasnikov // Bulletin of NTU "KhPI". Series: Dynamics and strength of machines. - Kharkiv: NTU "KhPI", 2017. - № 39 (1261). - C. 23-26. - Bibliogr.: 11. ISSN 2078-9130.

Відомості про авторів / Сведения об авторах / About the Authors

Красніков Сергій Васильович, кандидат технічних наук, доцент, Харківський національний автомобільно-дорожній університет, тел. (+038057) 707-37-30, e-mail: vsevakr@yandex.ru.

Красников Сергей Васильевич, кандидат технических наук, доцент, Харьковский национальный автомобильнодорожный университет, тел. (+038057) 707-37-30, e-mail: vsevakr@yandex.ru.

Krasnikov Sergij Vasyl'ovych, Candidate of Technical Sciences, Associate Professor, Kharkiv National Automobile and Highway University, tel.: (+038057) 707-37-30, e-mail: vsevakr@yandex.ru. 